\title{
Thyroid hormone treatment and SARS-CoV-2 infection
}

\author{
Efthymia Pappa $\mathbb{1}^{1}{ }^{1} \cdot$ Pagona Gourna $^{1} \cdot$ Georgios Galatas ${ }^{1} \cdot$ Asimina Romiou ${ }^{1} \cdot$ Ifigeneia Kiki $^{1}$ • \\ Lemonia Panagiotou' ${ }^{1}$. Constantinos Christopoulos ${ }^{1}$
}

Received: 27 November 2021 / Accepted: 6 December 2021 / Published online: 16 January 2022

(c) The Author(s), under exclusive licence to Springer Science+Business Media, LLC, part of Springer Nature 2021

It has recently been reported that the incidence of COVID19 might be higher in people who are on thyroid hormone substitution treatment (THS) with levothyroxine [1]. The significance of such an association is obvious, given that levothyroxine is one of the most prescribed medications worldwide (currently the second most prescribed drug in the USA) [2]. Based on experimental evidence from animal models of coronavirus disease, it has been speculated that thyroid hormones propagate cellular internalization and replication of SARS-Cov-2 through interaction with plasma membrane integrins [3].

We examined the prevalence of THS in a cohort of hospitalized patients with COVID-19 and compared it with that of controls. We also examined whether there was an association of levothyroxine treatment with in-hospital mortality in the same cohort of hospitalized COVID-19 patients.

The COVID-19 cohort consisted of 170 consecutive admissions (median age 62.7 years, $57.6 \%$ male) to the COVID-19 Unit of the Department of Internal Medicine of a tertiary general hospital in Athens, Greece. The control group consisted of 170 randomly selected, age- and sexmatched non-COVID patients who had been admitted to the same hospital department during the year preceding the study. All data were fully anonymized and collected according to Greek legislation.

The results are summarized in Table 1. There was no statistically significant difference in the percentage of patients who were on levothyroxine between the COVID-19 and the control group (18.2\% versus $16.5 \%, p=0.67)$. Patients with COVID-19 who were on levothyroxine had a lower case fatality rate compared to those who were not on THS treatment although the difference was of marginal

Efthymia Pappa

pappaefi@yahoo.gr

1 First Department of Internal Medicine, Sismanoglio General Hospital, Athens 15126, Greece statistical significance $(6.6 \%$ versus $20,9 \%, p=0.06)$. Multivariate logistic regression analysis using death as dependent variable and age, sex and THS as independent variables showed that COVID-19 patients receiving levothyroxine had a lower risk of in-hospital death (Adjusted Odds Ratio 0.23 (95\% confidence interval 0.05-1.17)).

Our results are at variance with those reported recently by a French group (Bacle et al.) who found that the percentage of hospitalized COVID-19 patients taking levothyroxine was almost double that of controls (11.1\% versus $6.3 \%)$ [1]. The authors concluded that patients on THS might be at increased risk of contracting COVID-19. Although our sample size would not permit detection of small increases in COVID-19 hazard associated with THS, our study had sufficient statistical power $(>80 \%)$ to detect an increase of the magnitude seen in the study by Bacle et al. However, it should be noted that the prevalence of THS in our control group was much higher compared to the control group of Bacle et al. (16.5\% versus $6.3 \%, p<0.001)$. There is evidence that THS is overused in the Greek population and it has been argued that up to $60 \%$ of subjects who receive levothyroxine have no thyroid disease [4]. Supposing that this also applies to the patients of our study, our results are more likely to reflect the impact of levothyroxine rather than that of thyroid disease on COVID-19 hazard.

In keeping with our results, population based studies utilizing insurance data and health system records have shown that being on THS is not a risk factor for acquiring SARS-CoV-2 infection [5-7]. Our finding of lower mortality in COVID-19 patients receiving levothyroxine, if confirmed in larger studies may lead to new therapeutic opportunities. There is experimental evidence that thyroid hormones play a lung-protective role by promoting alveolar fluid clearance and inhibiting fibrosis [8, 9]. Both alveolar fluid accumulation and pulmonary interstitial fibrosis are important drivers of mortality and morbidity in SARS-CoV2 infection. Moreover, the non-thyroidal illness syndrome, characterized by decreased peripheral levels of thyroid hormones combined with lack of a reciprocal increase in 
Table 1 Frequency of levothyroxine (T4) treatment in COVID-19 patients and controls, and mortality of COVID-19 patients according to whether they were on levothyroxine.

\begin{tabular}{|c|c|c|c|c|c|c|}
\hline & $N$ & Mean age (Range) & On T4 $N(\%)$ & $\begin{array}{l}\text { Mortality of COVID-19 } \\
\text { on T4 (\%) }\end{array}$ & $\begin{array}{l}\text { Mortality of COVID-19 not } \\
\text { on T4 (\%) }\end{array}$ & \\
\hline COVID-19 patients & 170 & $62.3(21-90)$ & $31(18.2)$ & 6.5 & 20.9 & $p=0.06$ \\
\hline Male & 98 & $60.9(21-90)$ & $8(8.2)$ & 0.0 & 21.1 & $p=0.35$ \\
\hline Female & 72 & $64.1(37-90)$ & $23(31.9)$ & 8.7 & 20.4 & $p=0.21$ \\
\hline CONTROL patients & 170 & $62.3(23-90)$ & $28(16.5)$ & & & \\
\hline Male & 98 & $61.0(23-90)$ & $8(8.2)$ & & & \\
\hline Female & 72 & $64.1(37-90)$ & $20(27.8)$ & & & \\
\hline
\end{tabular}

TSH is often seen in COVID-19 patients and has been associated with adverse prognosis [10-13]. Against this background, the results of a clinical trial of inhaled triiodothyronine in patients with acute respiratory distress syndrome (ARDS) including COVID-ARDS are awaited with interest $[14,15]$.

Author contributions Conceptualization and design: CC and EP. Data collection and analysis: EP, PG, GG, AR, IK, LP. The first draft of the manuscript was written by $\mathrm{CC}$ and EP and all authors commented on previous versions and approved the final manuscript.

\section{Compliance with ethical standards}

Conflict of interest The authors declare no competing interests.

Ethics approval This is a retrospective observational study involving statistical analysis of fully anonymized patient data. Ethical approval was waived by our institution's Research and Ethics Committees.

Publisher's note Springer Nature remains neutral with regard to jurisdictional claims in published maps and institutional affiliations.

\section{References}

1. A. Bacle, Y. Malledant, M. Mercerolle, C. Pronier, N. Nesseler, C. Barbazan, R. Garlantezec, Thyroid substitution may be a risk factor for Covid-19. Endocrine 73(3), 507-508 (2021). https://doi. org/10.1007/s12020-021-02791-1

2. S.P. Kane, ClinCalc DrugStats Database. https://clincalc.com/ DrugStats/ (2021) Accessed November 2021.

3. P.J. Davis, H.Y. Lin, A. Hercbergs, K.A. Keating, S.A. Mousa, Coronaviruses and Integrin $\alpha v \beta 3$ : does thyroid hormone modify the relationship? Endocr. Res. 45(3), 210-215 (2020). https://doi. org $/ 10.1080 / 07435800.2020 .1767127$

4. S. Livadas, C. Bothou, I. Androulakis, A. Boniakos, N. Angelopoulos, L. Duntas, Levothyroxine replacement therapy and overuse: a timely diagnostic approach. Thyroid 28, 1580-1586 (2018). https://doi.org/10.1089/thy.2018.0014

5. M. van Gerwen, M. Alsen, C. Little, J. Barlow, L. Naymagon, D. Tremblay, C.F. Sinclair, E. Genden, Outcomes of patients with hypothyroidism and COVID-19: A Retrospective Cohort Study. Front. Endocrinol. 11, 565 (2020). https://doi.org/10.3389/fendo. 2020.00565

6. T.H. Brix, L. Hegedüs, J. Hallas, L.C. Lund, Risk and course of SARS-CoV-2 infection in patients treated for hypothyroidism and hyperthyroidism. Lancet Diabetes Endocrinol. 9(4), 197-199 (2021). https://doi.org/10.1016/S2213-8587(21)00028-0

7. S.Y. Kim, D.M. Yoo, C.Y. Min, H.G. Choi, The effects of previous thyroid disease on the susceptibility to, morbidity of, and mortality due to COVID-19: A Nationwide Cohort Study in South Korea. J. Clin. Med. 10(16), 3522 (2021). https://doi.org/10.3390/ jcm10163522

8. M. Bhargava, M.R. Runyon, D. Smirnov, J. Lei, T.J. Groppoli, C. N. Mariash, O.D. Wangensteen, D.H. Ingbar, Triiodo-L-thyronine rapidly stimulates alveolar fluid clearance in normal and hyperoxia-injured lungs. Am. J. Respiratory Crit. Care Med. 178 (5), 506-512 (2008). https://doi.org/10.1164/rccm.200709$14290 \mathrm{C}$

9. G. Yu, A. Tzouvelekis, R. Wang, J.D. Herazo-Maya, G.H. Ibarra, A. Srivastava, J. de Castro, G. Deluliis, F. Ahangari, T. Woolard, N. Aurelien, R. Arrojo E Drigo, Y. Gan, M. Graham, X. Liu, R.J. Homer, T.S. Scanlan, P. Mannam, P.J. Lee, E.L. Herzog, A.C. Bianco, N. Kaminski, Thyroid hormone inhibits lung fibrosis in mice by improving epithelial mitochondrial function. Nat. Med. 24(1), 39-49 (2018). https://doi.org/10.1038/nm.4447

10. R. Baldelli, E. Nicastri, N. Petrosillo, L. Marchioni, A. Gubbiotti, I. Sperduti, P. Di Giacinto, L. Rizza, F. Rota, M. Franco, A. Lania, G. Aimaretti, G. Ippolito, P. Zuppi, Thyroid dysfunction in COVID-19 patients. J. Endocrinological Investig. 44(12), 2735-2739 (2021). https://doi.org/10.1007/s40618-021-01599-0

11. S. Lang, Y. Liu, X. Qu, R. Lu, W. Fu, W. Zhang, H. Wang, T. Hong, Association between thyroid function and prognosis of COVID-19: A Retrospective Observational Study. Endocr. Res. 46(4), 170-177 (2021). https://doi.org/10.1080/07435800.2021. 1924770

12. J. Gong, D.K. Wang, H. Dong, Q.S. Xia, Z.Y. Huang, Y. Zhao, X. Chen, F. Yuan, J.B. Li, F.E. Lu, Prognostic significance of low TSH concentration in patients with COVID-19 presenting with non-thyroidal illness syndrome. BMC Endocr. Disord. 21(1), 111 (2021). https://doi.org/10.1186/s12902-021-00766-x

13. F. Beltrão, D. Beltrão, G. Carvalhal, F. Beltrão, A. Brito, K. Capistrano, I. Bastos, F. Hecht, C. Daltro, A.C. Bianco, M. Gonçalves, H.E. Ramos, Thyroid hormone levels during hospital admission inform disease severity and mortality in COVID-19 Patients. Thyroid 31(11), 1639-1649 (2021). https://doi.org/10. 1089/thy.2021.0225

14. University of Minnesota: Phase II randomized, intervention versus non-intervention, multi-center study of the effects of thyroid hormone (T3) on Extravascular Lung Water (EVLW) in Subjects With Acute Respiratory Distress Syndrome (ARDS). NCT04115514. https://clinicaltrials.gov/ct2/show/NCT04115514/ (2021). Accessed November 2021.

15. K. Galioto, J. Olson, Experimental therapy may speed COVID recovery. Star Tribune. https://www.startribune.com/hormoneboost-could-be-covid-19-key/572944532 (2020). Accessed November 2021. 